\title{
Economics and Employment Generation of Bamboo-Based Enterprises: A Case Study from Eastern Bangladesh
}

\author{
M. Parvez Rana - Sharif Ahmed Mukul • M. Shawkat Islam Sohel • \\ Mohammad Shaheed Hossain Chowdhury • Sayma Akhter • \\ M. Qumruzzaman Chowdhury • Masao Koike
}

Accepted: 25 November 2009/Published online: 3 December 2009

(C) Steve Harrison, John Herbohn 2009

\begin{abstract}
An exploratory survey was carried out to assess economics and employment generation of the trade of bamboo and bamboo-based secondary products in the eastern Bangladesh, to obtain reliable information about their status, socio-economic significance, production and marketing. The study was undertaken over 30 bamboo-based enterprises in a suburban market of eastern Bangladesh, to investigate regional product details, economic profitability and employment opportunities. The sample entrepreneurs, corresponding to about $25 \%$ of the bamboo enterprise population were interviewed using a semi-structured questionnaire. About 202 full and part-time workers were employed in the factories, under categories of artisan (who manufactured secondary products). The average number of worker's in the large, medium and small factories were 9 (artisan 40\%), 6.45 (artisan 35\%) and 5 (artisan 25\%) respectively. The study revealed that there was always a satisfied demand of skilled artisans. Most of the workers were relatively newly employed (not more than 5 years). The daily wage rate varied between 70 and 130 Tk. (\$US 1 equals approximately 70 Bangladeshi Taka (Tk.), as at December 2008). Bambusa balcooa was the most utilized species (39.96\%) in terms of monetary value. The price of a single B. balcooa culm in the local market was Tk. 160-210. Nine sizes of articles under seven bamboo categories were identified, these being bera $\left(36^{\prime \prime} \times 120^{\prime \prime}\right.$ and $\left.72^{\prime \prime} \times 96^{\prime \prime}\right)$, bookshelf $\left(36^{\prime \prime} \times 24^{\prime \prime}\right)$, chaluni
\end{abstract}

M. P. Rana $(\bowtie) \cdot$ M. S. I. Sohel · S. Akhter · M. Q. Chowdhury

Department of Forestry and Environmental Science, Shahjalal University of Science and Technology, Sylhet 3114, Bangladesh

e-mail: parvez_200207@yahoo.com

\section{S. A. Mukul}

Institute of International Forestry and Forest Products, Dresden University of Technology, 01735 Tharandt, Germany 
$\left(12^{\prime \prime} \times 12^{\prime \prime}\right)$, chatai $\left(48^{\prime \prime} \times 60^{\prime \prime}\right.$ and $\left.36^{\prime \prime} \times 48^{\prime \prime}\right)$, jhuri, rickshaw hood and tukri. Net average profit per article was the highest for rickshaw hoods (Tk. 400 at the retailer stage). The total expected annual income for an enterprises from all articles types sold was estimated to be Tk. 85,800. Three distinct marketing channels were identified for selling bamboo and value-added secondary products. The study also generated policy implications for effective management of bamboo-based enterprises.

Keywords Small-scale enterprise - Labour condition - Marketing channel . Non-timber forest product

\section{Introduction}

Bamboo has become an imperative trade commodity globally, in both local and regional market, and provides direct or indirect livelihood support to approximately 2.5 billion people (Banik 1995; INBAR 1999). INBAR (1999) valued the worldwide domestic trade and subsistence use of bamboo at about US\$ 4.5 billion per annum with another US\$2.7 billion generated from bamboo exports. In Asia, with about 1,000 naturally occurring species, bamboo industries are now thriving (Dransfield and Widjaja 1995; Lobovikov et al. 2007). In that region bamboo is an essentially important part of the livelihoods and culture of tribal and rural people as their primary source of housing material (for thatching, roofing, flooring, fencing), food (young shoots), agricultural implements and domestic utensils (Vantomme et al. 2002). In some Asian countries, including China, it is a valuable raw material for a booming non-timber forest product (NTFP) industry that locally generates huge employment opportunities and cash flows (Ruiz-Perez et al. 1999).

In Bangladesh, bamboo-often called 'poor man's timber' —is the most important NTFP, and plays a crucial role in regional markets (Khan and Khan 1994). Thirty-three species of bamboo (represented by nine genera and including 18 naturally occurring species) have so far been reported from throughout the country (Banik 1998; Bystriakova et al. 2003; Latif 2008). Bamboos are available in both forest and non-forest areas and are categorized into two broad groups with several overlapping species - forest bamboos and village bamboos (Zabala 1990). Among forest bamboo, Melocanna baccifera is the most widely occurring bamboo species of Bangladesh; other species including Bambusa tulda, Dendrocalamus longispathus, Oxytenanthera nigrociliata and Schizostachyum dullooa occur sporadically in association with Melocanna and in isolation forming small patches of pure bamboo vegetation (Latif 2008). In all village households except saline and low-lying marshy areas, bamboo has been cultivated on a small scale since time immemorial for meeting day-to-day needs. About 15 species of bamboo have been cultivated in the plains of Bangladesh. Among them Bambusa balcooa, Bambusa vulgaris, and Bambusa nutans are most common (Miah et al. 2002; Latif 2008). The total growing stock of the village bamboo groves is 0.80 tonnes, while naturally regenerated bamboo growing stock amounts is $0.19 \mathrm{mt}$ (Lobovikov et al. 2007). 
Bamboos are increasingly being used as a wood substitute in both rural and urban areas, due to their diverse uses (Wong 2004). Bamboo scaffolding used during construction of buildings, including high-rise structures, looks set to stay as a simple, inexpensive technology even in today's world of modern innovations (Wong 2004). About 76\% of farmers of Bangladesh have been using bamboo for household construction and fencing (Latif 2008). Bamboos have also been used on more than $65 \%$ of farms as agricultural implements (Miah et al. 2002; Latif 2008). Between 1981 and 2000 the annual gross consumption of bamboo in Bangladesh was about $700 \mathrm{M}$ culms, corresponding to almost $1 \mathrm{mt}$ of which $28.5 \%$ (200 M culms) came from the state forests and $71.5 \%$ (500 M culms) were logged in village forests (Lobovikov et al. 2007). During 2001-2002 Bangladesh earned Tk. 37.5 M from exporting bamboo and bamboo-based manufactured products (Vantomme et al. 2002). However, the estimated annual national loss of natural bamboo area is about 2.3\% (Banik 1993). The Bangladesh Small and Cottage Industries Corporation (BSCIC) estimated that there are about 45,000 registered small-scale cottage enterprises located throughout the Bangladesh that consume about $46 \mathrm{M}$ bamboo culms annually, and about 300,000 people are employed in bamboo cutting and collecting from forests (Latif 2008).

Despite the high value and widespread use of bamboo, most of the studies are concentrated mainly on managerial or silvicultural traits (e.g. Banik 1998; Miah et al. 2002; Kamruzzaman et al. 2008). However, the economics and employment generation characteristics of bamboo-based enterprise are vital to the continuing development of the country's economy, especially in the rural sector (Alamgir et al. 2005, 2007).

Little reliable information is available about the status, socio-economic significance, production and marketing of bamboo. The study reported here was designed to examine the production and marketing of bamboo-based products in the eastern Bangladesh, and its potential contribution to regional socio-economic development. A further objective was to generate policy implications for efficient management of this enterprise and to develop new strategies for improvement of small-scale bamboo-based enterprises.

\section{The Study Site}

The study was performed in Chock bazaar (pouroshova) in Sadar upazila (subdistrict and administrative entity) of Comilla district, eastern Bangladesh (Fig. 1). The area is located between $23^{\circ} 29^{\prime}-23^{\circ} 48^{\prime} \mathrm{N}$ and $90^{\circ} 53^{\prime}-91^{\circ} 04^{\prime} \mathrm{E}$ and is bounded by Burichang upazila and Tripura state of India in the north, Laksham and Chauddagram upazila in the south, Tripura State of India in the east, and Barura upazila in the west. Rajendrapur forest, Sal forest and Lalmai hills are most notable because these were the only forest in the area. Sal forest and Lalmai hills have historical importance and also a well recognized bamboo market in the eastern region of Bangladesh. Besides this bamboo produced in Comilla is sold Dhaka, which is within reasonable transport distance (about $97 \mathrm{~km}$ ). Comilla district acts as the major supply source of bamboo and related products to adjacent districts 


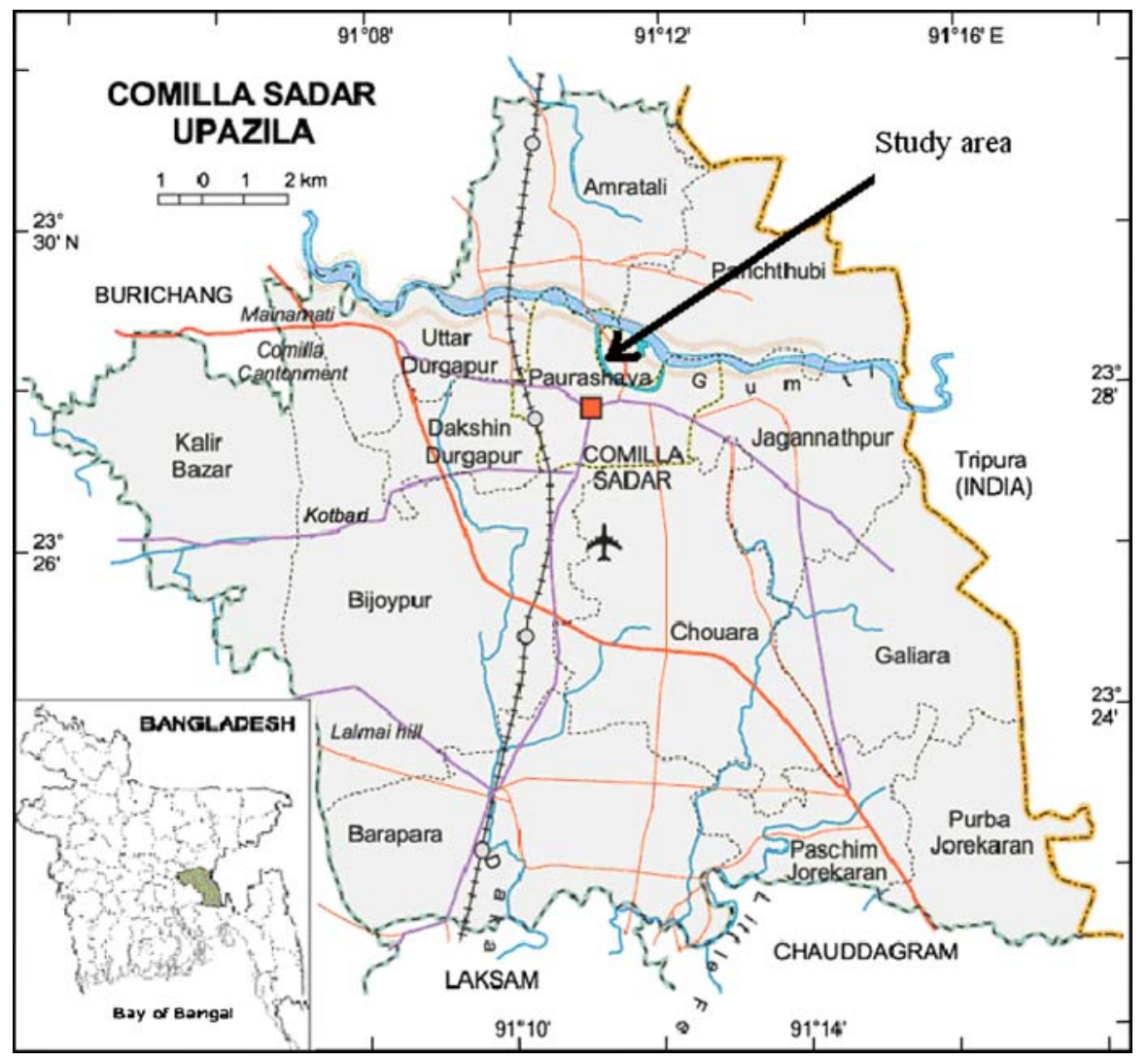

Fig. 1 Map of the study site. Source: Banglapedia (2009)

because of the relatively low bamboo price due to year-round supply from nearby hilly areas and local homesteads. This old market, which spreads over a quarter of a kilometer of roading, can easily be accessed from any part of Bangladesh.

\section{Research Method}

Among 12 upazilas within the Comilla district of eastern Bangladesh, the Comilla Sadar upazila was selected purposively because it is an old and popular bamboobased market and supplies a major portion bamboo and bamboo-based products in eastern Bangladesh. A multistage random sampling method was applied to locate the market and entrepreneurs for the study within the upazila as the primary sampling unit and ultimate sampling unit, respectively. An entrepreneur was defined as a person who owns a temporary or permanent bamboo-based enterprise, purchases bamboo and resells it either in raw form (bamboo culms or poles) or as manufactured secondary products. The entrepreneurs were identified through preliminary field investigation during July to December 2008, which involved an 
interview to ascertain important socio-economic parameters (including sex, age, education, occupation, family members involved in the bamboo-based enterprise, income from this enterprise, number of years in the profession) to select respondents for detailed study. Thirty entrepreneurs, corresponding to about $25 \%$ of local population (of size 120), were interviewed. Based on annual income from sale of bamboo products the enterprises were later categorized into three distinct classes (large-an income above Tk. 135,000/year, medium-income between Tk. 80,000 and 135,000/year, and small—income below Tk. 80,000/year).

A semi-structured questionnaire was used to collect demographic and socioeconomic background data on the entrepreneurs, financial data, and data on the supply and sources of raw materials, manufactured products, and status of workers (i.e. persons who worked in the local bamboo shops either in permanent or temporary basis). All qualitative and quantitative data were collected in local terms and units. The average annual incomes from different types of bamboo (unprocessed) were estimated through questioning of entrepreneurs. The approximate incomes of the local bamboo-based enterprises were estimated through careful questioning of entrepreneurs where the values of total inputs (e.g. raw materials, transportation, wages of the workers, an allowance towards self-labour, fixed costs of permanent structures, depreciation, rent and electricity payments, taxes on income and where applicable interest of loans) and outputs (from sale of primary and secondary products) were estimated at the current price. Production costs of the bamboo-based products were determined from the average value of total inputs required (excluding wages of workers and factory operating costs).

\section{Study Findings}

\section{Employment Generation and Labour Force Employed}

All entrepreneurs were found to be male, with 50\% in the age range 41-50 years (Table 1). The literacy rate was high-47\% had completed primary education, $33 \%$ junior secondary, and $13 \%$ secondary or above, compared to the national literacy rate of $65 \%^{1}$ (BBS 2009). Most of the entrepreneurs had been engaged in the profession for more that 10 years. The trade of bamboo and secondary products made from bamboo was the main earning source for about 43 and $37 \%$ of respondents, respectively. Other major income generating occupations included agriculture (10\%) and business (excluding bamboo trade, $7 \%$ ).

The 30 survey factories employed 202 workers. Among those, 55\% were temporary workers employed on a day wage basis and $45 \%$ were permanent workers on a monthly payment basis. These included artisans (craftsmen) (locally termed as karigar) who manufacture the bamboo-based secondary products. According to the amount of cash earned from selling bamboo and bamboo-based secondary products the enterprises were grouped as large $(n=9$; income above Tk. 135,000/year), medium ( $n=11$; income between Tk. 80,000 and 135,000/year),

\footnotetext{
${ }^{1}$ Literacy of individuals is defined as ability to read and write their name.
} 
Table 1 Profiles of the employing labour in the survey enterprises

\begin{tabular}{|c|c|c|c|c|c|}
\hline \multirow[t]{2}{*}{ Variable } & \multirow[t]{2}{*}{ Class } & \multicolumn{2}{|c|}{ Entrepreneur $(n=30)$} & \multicolumn{2}{|c|}{ Artisan $(n=202)$} \\
\hline & & Frequency & $\begin{array}{l}\text { Relative } \\
\text { frequency }(\%)\end{array}$ & Frequency & $\begin{array}{l}\text { Relative } \\
\text { frequency (\%) }\end{array}$ \\
\hline \multirow[t]{7}{*}{ Age } & $<10$ Years & - & - & 6 & 3 \\
\hline & 10-20 Years & - & - & 13 & 6 \\
\hline & 21-30 Years & 3 & 10 & 68 & 34 \\
\hline & $31-40$ Years & 8 & 27 & 97 & 48 \\
\hline & 41-50 Years & 15 & 50 & 15 & 7 \\
\hline & 51-60 Years & 3 & 10 & 3 & 1 \\
\hline & $60>$ Years & 1 & 3 & - & - \\
\hline \multirow[t]{2}{*}{ Sex } & Male & 30 & 100 & 169 & 84 \\
\hline & Female & - & - & 33 & 16 \\
\hline \multirow{4}{*}{$\begin{array}{l}\text { Education } \\
\text { (completed) }\end{array}$} & Illiterate & 2 & 7 & 100 & 50 \\
\hline & Primary & 14 & 47 & 74 & 37 \\
\hline & Junior secondary & 10 & 33 & 24 & 12 \\
\hline & Secondary or above & 4 & 13 & 4 & 2 \\
\hline \multirow{3}{*}{$\begin{array}{l}\text { Number of year } \\
\text { in the profession }\end{array}$} & $1-5$ Years & 3 & 10 & 124 & 61 \\
\hline & $6-10$ Years & 7 & 23 & 61 & 30 \\
\hline & $10>$ Years & 20 & 67 & 17 & 8 \\
\hline
\end{tabular}

and small ( $n=10$; income below Tk. 80,000/year). The average number of worker's in the large, medium and small factories were 9 (artisan, 40\%), 6.45 (artisan, 35\%) and 5 (artisan, 25\%) persons, respectively. The majority of the worker's were adult male (84\%) and the modal age class with $48 \%$ of the workers was 31-40 years. The literacy rate of the workers or proportion who completed primary school or above was 50\%. All the children (under 10 years, 3\%) and female artisans $(16 \%)$ were employed on a temporary basis. They generally received a lower wage than adult male workers; the daily wage rate of adult males and females and of children during the period were Tk. 130, 90 and 70, respectively.

About $8 \%$ of the permanent workers of the enterprises had been in their profession for more than 10 years, $30 \%$ for $6-10$ years and $61 \%$ for $1-5$ years, and. There was, however, always a demand of skilled or experienced artisans, while the demand for workers generally decreased with increase of their age.

Utilization of Bamboo and Bamboo-Based Secondary Products in the Study Area

Four species of bamboo-viz. Bambusa balcooa, Bambusa tulda, Bambusa vulgaris, Melocanna baccifera-were frequently traded locally and used for manufacturing secondary products. B. balcooa was the most utilized species 
(40.0\%; annual market value average 330,201 Tk.) followed by $M$. baccifera (26.5\%, 219,001 Tk.), B. tulda (22.9\%, 189,000 Tk.) and B. vulgaris $(10.7 \%, 88,041$ Tk.). B. balcoa was sold primarily without any modifications, being favoured for use by urban consumers for building construction purpose including bamboo scaffolding during construction and for making roofing frameworks. The other three species were observed to be used for making fences, mats and domestic utensils. $M$. baccifera was also sold in unprocessed state. The price of bamboo culms depended on their maturity and quality (usable length, thickness, colour). B. balcooa sold for Tk. 160-210 per 100 culms (compared to purchase price of Tk. 90-100), whereas M. baccifera sold for Tk. 550-700 per 100 culms (compared to purchase price of Tk. 325-425). Prices were also influenced by seasonal demand (with peak season of October-April and off-peak season of May-September), product availability and the influence of the middlemen.

Table 2 lists articles produced from various bamboo species with their trade name, common uses and selling price in the local market. Bamboo mats and fences were the two most widely traded articles, and were available in various sizes. The prices of bamboo articles depended on the amount of bamboo and other materials used, and the time and expertise required by artisans to manufacture them. There was no organized marketing of the finished products in the study area, entrepreneurs selling their products sporadically in local markets directly or through intermediaries, with no uniform pricing. The small size of the enterprises and the poor financial position of the artisans creates serious problems for product marketing. Three distinct marketing channels (i.e. producer $\rightarrow$ consumer; producer $\rightarrow$ middlemen $\rightarrow$ retailer $\rightarrow$ consumer, and producer $\rightarrow$ middlemen $\rightarrow$ wholesaler $\rightarrow$ consumer) were identified for selling bamboo and value-added secondary products. From Table 2 it is clear how the artisans are being exploited by middlemen. Depending on the type of article the price between the factory and retailer was found to vary between Tk. 15 and Tk. 150. This was due to lack of marketing knowledge of the respondents and lack of market information as well as marketing facilities. The variation between factory and retail price might be higher than the stated markup, because the middlemen generally overstate their real price to obtain a higher percentage of benefit.

\section{Profitability of Bamboo-Based (Secondary Products) Enterprises}

Table 3 reports average production cost, average selling price and average profit from various items, average numbers of items sold annually and income of enterprises. From the viewpoint of net average profit per article, rickshaw hood account for the highest value (Tk. 150) followed by bookshelf (Tk. 40). Annual income per entrepreneur was also highest for rickshaw hood (Tk. 30,000) followed by bookshelf, 36" $\times 24^{\prime \prime}$ size (Tk. 9,200). Chatai (matting, for construction), $36^{\prime \prime} \times 48^{\prime \prime}$ size, accounted for the highest number of articles sold annually (340), followed by chatai, $48^{\prime \prime} \times 60^{\prime \prime}$ size (300). The total annual net income for an enterprise was estimated to be Tk. 85,800 from all the articles. 


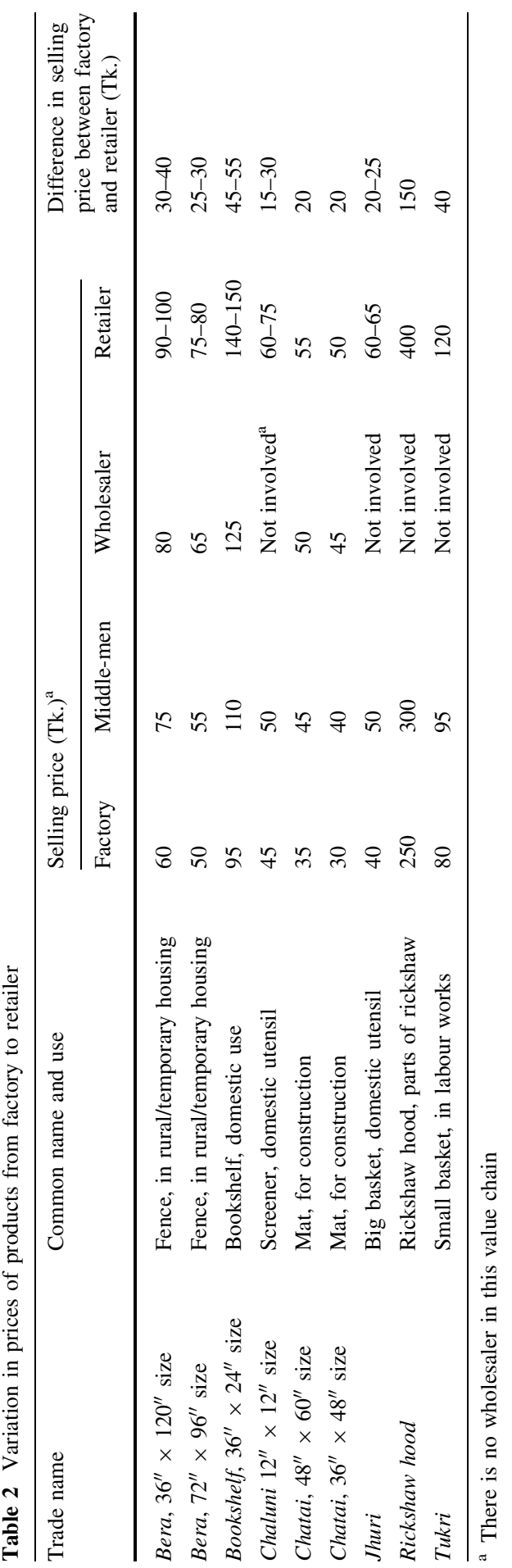




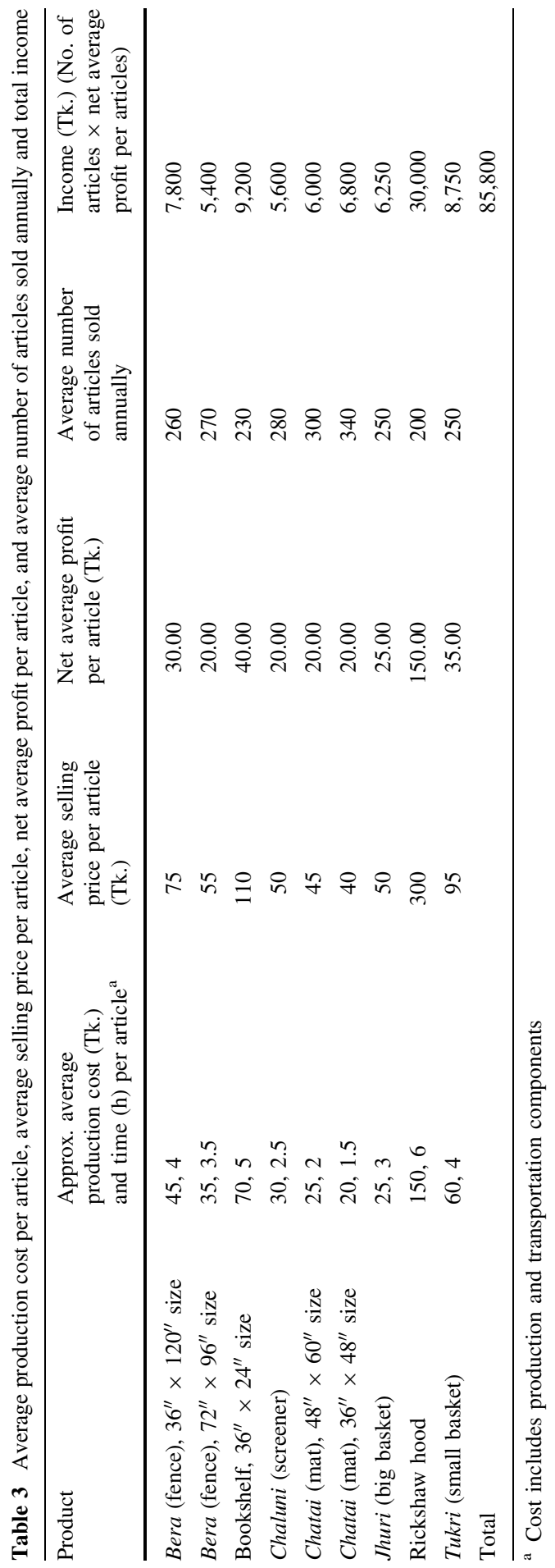




\section{Concluding Comments}

Bamboo and bamboo-based secondary product trading is a profitable business in Bangladesh and a potential sector of employment generation for the rural people. Bamboo is used extensively by local communities and plays an important role in subsistence strategies for many rural populations. Bamboo enterprises are continuously sustaining the national economy through providing employment opportunities for poor people, including raw material collection, processing and marketing. The analysis reported here indicates that small-scale bamboo-based enterprises could be developed more widely throughout the rural areas of Bangladesh for socioeconomic development.

Most of the bamboo products are in high demand but production is limited due to scarcity of raw materials and also high culm price during the May-September period of limited supply. There is an urgent need to utilize the remaining natural bamboo stocks on a sustainable basis, expand their cultivation on encroached forest land and khas land (unused government land) in rural homesteads. The majority of the supply comes during the monsoon period and as all the bamboo is stored in open space this seasonal gap sometimes reduces the quality of bamboo thereby reducing the value. Government and NGOs can work with the enterprises during that time through encouraging them to manufacture secondary products and promote these value-added products in urban markets. The present loan approval procedure, conditions and interest rates also need to be revised and made more flexible to support the entrepreneurs.

Acknowledgments We wish to thank all the respondents of the study for sharing their information. Thanks also to the responsible editor Dr. Steve Harrison of The University of Queensland and the unknown reviewers for their innumerable efforts and advice to enhance the quality of this manuscript.

\section{References}

Alamgir M, Jashimuddin M, Bhuiyan MAR (2005) Employment generation and economics of cane based furniture enterprises of Chittagong, Bangladesh. J Bamboo Rattan 4(3):279-292

Alamgir M, Mezbahuddin M, Jashimuddin M (2007) Role of bamboo based cottage industry in economic upliftment of rural poor of Chittagong, Bangladesh. J Bamboo Rattan 6(4):55-63

Banglapedia (2009) National encyclopedia of Bangladesh. Dhaka: Asiatic Society of Bangladesh. Retrieved September 3, 2009, from www.banglapedia.org

Banik RL (1995) Diversities, reproductive biology and strategies for germplasm conservation of bamboos. In: Rao VR, Rao AN (eds) Bamboo and Rattan genetic resources and use. Proceedings of the First INBAR biodiversity, genetic resources and conservationworking group. INBAR-IPGRI, Rome, pp 1-22

Banik RL (1998) Bamboo resources, management and utilization in Bangladesh. In: Rao AN, Rao VR (eds) Bamboo conservation, diversity, ecogeography, germplasm, resource utilization and taxonomy. Proceedings of training course cum workshop 10-17 May, Kunming and Xishuangbanna, Yunnan, China, pp 137-150

BBS (Bangladesh Bureau of Statistics) (2009) Statistical year book of Bangladesh. Ministry of Planning, People's Republic of Bangladesh

Bystriakova N, Kapos V, Lysenko I, Stapleton CMA (2003) Distribution and conservation status of forest bamboo biodiversity in the Asia-Pacific Region. Biodivers Conserv 12(9):1833-1841

Dransfield S, Widjaja EA (1995) Plant resources of South-east Asia, No. 7. Bamboos, Backhuys 
International Network for Bamboo and Rattan (INBAR) (1999) Socio-economic issues and constraints in the bamboo and rattan sectors. INBAR's assessment. INBAR working paper No. 23. Beijing

Kamruzzaman M, Saha SK, Bose AK, Islam MN (2008) Effects of age and height on physical and mechanical properties of bamboo. J Trop For Sci 20(3):211-217

Khan SA, Khan NA (1994) Non-wood forest products of Bangladesh: an overview. Bangladesh J For Sci 23(1):45-50

Latif MA (2008) Bamboo species, their distribution, habitat, rehabilitation and uses in Bangladesh. Document no-1, market development of bamboo and rattan products with potentials, Bangladesh Forest Research Institute, Chittagong

Lobovikov M, Paudel SM, Piazza HR, Wu J (2007) World bamboo resources, a thematic study prepared in the framework of the global forest resources assessment. Non-wood forest products series no. 18. Food and agriculture organization of the United Nations (FAO). Rome, pp 55-60

Miah MD, Ahmed R, Uddin MB (2002) Indigenous management of bamboo plantations in the rural homesteads of floodplain areas of Bangladesh. Int J For Usuf Mngt 3(1 \& 2):35-40

Ruiz-Perez M, Zhong M, Belcher B, Xie C, Fu M, Xie J (1999) The role of bamboo plantations in rural development: the case of Anji County, Zhejiang, China. Wor Develo 27(1):101-104

Vantomme P, Markkula A, Leslie RN (2002) Non-wood forest products in 15 countries of tropical Asia: an overview. FAO-RAP, Bangkok

Wong KM (2004) Bamboo- the amazing grass, a guide to the diversity and study of bamboos in Southeast Asia. International plant genetic resources institute (IPGRI) and University of Malaya, Selangor, Darul Ehsan and Kuala Lumpur

Zabala NQ (1990) Agroforestry. Development of professional education in the forestry sector of Bangladesh. Institute of Forestry, University of Chittagong, Chittagong 